\title{
APRENDIZAGEM COLABORATIVA APOIADA POR UM JOGO NARRATIVO CULTURALMENTE CONTEXTUALIZADO
}

\author{
Marcos Alexandre Rose Silva \\ Junia Coutinho Anacleto \\ Laboratório de Interação Avançada - LIA \\ Departamento de Computação - Universidade Federal de São Carlos (UFSCar) \\ Caixa Postal 676 - 13.565-905 - São Carlos - SP - Brasil \\ $\{$ marcos_silva,junia\}@dc.ufscar.br
}

\begin{abstract}
Resumo: Atualmente as escolas têm encontrado muitos desafios educacionais para ensinar aos alunos algumas habilidades que fazem parte do processo de aprendizado e de vida, tais como: se expressar e trabalhar colaborativamente. Como também, os professores têm dificuldades para encontrar ferramentas que os apóiem a trabalhar em grupo com seus alunos de acordo com os seus objetivos pedagógicos, pois tais atividades dificilmente ocorrem naturalmente. Neste contexto este trabalho descreve um jogo narrativo para ser utilizado pelos professores, permitindo-os contar estórias colaborativamente com seus alunos. Este jogo permite 0 professor construir estórias contextualizadas à realidade sóciocultural dos alunos, utilizando um vocabulário comum durante a narração, considerando os mitos, crenças, conhecimento de um grupo de alunos, permitindo que eles se identifiquem com as estórias.
\end{abstract}

Palavras-chave: Jogos Narrativos, Jogos Computacionais, Contexto, Senso Comum, Educação, Role-Playing Game

\section{A CULTURALLY CONTEXTUALIZED NARRATIVE GAME TO SUPPORT COLLABORATIVE LEARNING}

Abstract: Nowadays, schools have a lot of educational challenges to teach some skills that are part of student's education and life, such as: teaching to students to express themselves and to work in group. Teachers do not easily find a tool to support them to work collaboratively with their students considering their pedagogical objectives. Activities to promote work in group can rarely occur spontaneously. Therefore, it is presented here an educational computer narrative game to support teachers work collaboratively with their students through contextualized storyteller to the student's socio-cultural reality, using common vocabulary during narrative, considering myths, beliefs and knowledge of students group and consequently enabling these students to identify and get interested in collaborate with the teacher and other students to develop the story.

Keywords: Narrative Game, Computer Game, Context, Common Sense, Education, Role-Playing Game 


\section{Introdução}

Muitos são os desafios educacionais que as escolas e, todos que participam dessa instituição, precisam superar para educar cidadãos; não apenas para o futuro profissional, mas também para a vida. Já é consenso entre muitos pesquisadores (FREIRE, 1996; PAPERT, 1985; VYGOSTSKY, 1987; PIAGET, 1998), que não basta apenas entregar um conjunto de informações aos alunos, é preciso prepará-los para pensar.

É necessário se preocupar com as necessidades básicas de aprendizagem - conhecimento, habilidades, atitudes e valores desde a infância do aluno, de modo que ele possa sobreviver, desenvolver sua qualidade de vida e estar apto a continuar aprendendo (GADOTTI, 1991).

Para Gadotti (2000) o conceito de educação sugere que o ensino na infância seja a base para uma educação continuada, integrada a todos os aspectos do desenvolvimento humano. Concentrando o processo ensino-aprendizagem do aluno, em sua necessidade, sua cultura. É necessário reconhecer o saber do educando, para que a partir dele possa se ter um contexto para construir um saber mais elaborado.

Piaget (1998) descreve que o processo de ensino-aprendizagem é mais eficaz quando o aluno participa da construção do seu conhecimento, fazendo o "seu" conhecimento e não apenas "aprendendo" o conhecimento.

Neste contexto, este trabalho relata a proposta de um jogo narrativo computacional, contextualizado ao conhecimento, à cultura do aluno, para apoiá-lo em compartilhar suas experiências com seus colegas de uma forma que seja natural e familiar a ele. Natural, pois a criança desde cedo conta sobre eventos que ela vive através de estórias e; Familiar, pois ao considerar a cultura do aluno na estória, poderá permitir a ele se identificar com os personagens, cenários e situações que ocorrem durante a narrativa, possibilitando-o se interessar pela estória e através dela compartilhar suas experiências, dificuldades e participar ativamente da estória.

\section{Desafios Educacionais}

A Unesco encomendou ao político francês Jacques Delors um relatório sobre a educação para o século 21. No relatório, Delors indica quatro pilares que devem moldar o aprendizado: aprender a aprender, aprender a fazer, aprender a conviver e aprender a ser (GADOTTI, 2000).

Aprender a Conviver - Para Alípio Casali (CASALI, 2005), a geração do século 21 enfrenta uma grave crise de convivência (socialização). Famílias dispersas, pais ausentes e o distanciamento de instituições tradicionais, como a igreja, deixam as crianças 
perdidas, sem referência. Com o enfraquecimento desses vínculos as crianças podem crescer com dificuldades para os relacionamentos sociais. Portanto, a escola não pode deixar de lado seu papel de socializar adequadamente.

Aprender a Ser - Muitas vezes há uma tendência de ensinar sobre as informações que acontecem em todo o mundo, pois há necessidade de conhecer e entender a globalização, porém é importante sempre valorizar o que acontece no país, estado, cidade, bairro que a criança vive (GADOTTI, 2000).

A globalização e a valorização da cultura local não são antagônicas, mas complementares. A escola ao considerar esse conjunto de conhecimento permitirá a criança também conhecer e entender sua realidade, formando assim, um cidadão que conhece e se preocupa com a democracia interna, exerce os direitos civis; um cidadão governante e não simplesmente governado.

Aprender a Aprender - A escola é o principal canal de acesso às necessidades básicas de aprendizagem - conhecimento, habilidades, atitudes e valores (GADOTTI, 1991); porém há outros veículos de informação, como o rádio, a televisão, clubes, biblioteca, internet e outros meios que a criança possui acesso. Portanto é necessário que a escola forneça uma base sólida para o aluno e trabalhe o seu senso crítico para ensiná-lo averiguar se o que lê, ouve ou vê é verdadeiro ou não, permitindo a ele continuar aprendendo, de uma maneira crítica, sabendo avaliar o conteúdo, sem ficar soterrado pela grande quantidade de informação disponível.

Aprender a Fazer - Após ter adquirido o conhecimento, a aluno tem que ser capaz de aplicá-lo. Para isso é necessário que ele tenha interesse e participe ativamente do que está aprendendo, para estar envolvido com o conteúdo que está sendo oferecido, de tal modo que possa participar de seu aprendizado ativamente, para assim planejar e tomar decisões em diversas situações que podem ocorrer em sua vida, com base no conhecimento aprendido.

A escola, por ter o compromisso com a promoção da cidadania e a qualidade de vida, é responsável por oferecer meios para que o aluno construa o seu conhecimento e, possua uma base sólida para aprender a conviver, a ser, a aprender e a fazer. Porém atividades para promover esses aprendizados raramente acorrem espontaneamente, professores e alunos precisam ter atividades e/ou ferramentas para apoiarem esse trabalho em sala de aula.

Atualmente algumas ferramentas têm despertado a atenção da escola para apoiar o professor no ensino, de modo a despertar o engajamento e o interesse do aluno, dentre elas encontram-se duas: o computador e o jogo.

\section{Jogos Computacionais}


Para Tarouco et al., (2004) o computador se constitui como uma poderosa ferramenta, que pode ter todas as suas potencialidades utilizadas com propósitos educacionais. O jogo pode se eficiente para facilitar o contato genuíno do aluno com o professor e com seus colegas, pois ele pode permitir uma comunicação mais agradável, divertida e produtiva (MARCATTO, 1996).

Por ter tais características surge a possibilidade de unir o computador e o jogo para formar uma ferramenta, o jogo computacional, capaz de contribuir para despertar o interesse e; melhorar a vinculação afetiva do aluno com as situações de aprendizagem (TAROUCO et al, 2004).

Existem vários tipos de jogos computacionais, de maneira geral podem ser classificados como: recreativos, cooperativos, narrativos e educacionais (ANACLETO, 2008). Os jogos narrativos permitem o jogador contar e/ou participar de estórias, narrando fatos, acontecimentos, cenários e, todos os detalhes necessários para compor uma estória. Essa estória não é simplesmente compreendida pelo jogador, ele contribui ativamente com a estória, define caminhos, toma decisões de uma forma espontânea.

Contar estórias colaborativamente permite ao jogador estar atento e interessado no que está acontecendo, de modo a entender e consequentemente contribuir com a estória. A fantasia existente nesses jogos permite ao jogador, em especial a criança, se sentir segura para poder se expressar, contar situações que ocorrem em sua vida, falar de suas dificuldades, pois para ela o que acontece na fantasia possui pouca ou nenhuma conseqüência na vida real (OKLANDER, 1978).

O envolvimento entre jogador e estória nos jogos narrativos pode ser explorado como uma forma de envolver o aluno com as pessoas que estão participando da estória, possibilitando-o se expressar, falar sobre suas experiências, suas dificuldades, permitindo que ele elabore de forma adequada as situações vivenciadas na escola, com a família e comunidade. Pois assim, 0 aluno pode compartilhar suas experiências com seus colegas bem como permitir ao professor acompanhar seu processo de aprendizado e elaboração dessas experiências, apoiando-o nas possíveis intervenções para a promoção do seu desenvolvimento saudável e seguro.

\subsection{0 potencial dos jogos narrativos}

O ato de contar estórias faz parte da vida de uma pessoa desde muito cedo, muitas vezes a criança pratica o contar estórias sem saber pronunciar as palavras corretamente, por exemplo, quando a criança arrasta um animal de brinquedo pelo chão, dizendo "Piu Piu", "Au au" ou "Moooo" ela está se expressando. Portanto, esse ato ocorre de uma forma simples e natural, permitindo a criança se expressar e também transmitir o que sabe, pensa e vive (CASSELL et al., 2001).

Através da estória, a criança pode conhecer, aprender e viver situações do mundo real de uma maneira que ela considera divertida 
e interessante. Ao permitir que o aluno conte estórias de uma maneira colaborativa com os seus colegas, o professor o permite aprender a conviver, ter contato, interagir com as outras pessoas e colaborar com elas de maneira a alcançar um objetivo comum, que pode ser construírem uma estória juntos do início ao fim.

Em um jogo narrativo, o aluno define caminhos durante a estória, cada aluno pode ser um personagem e através dele: fazer, falar e pensar, pois o aluno decide as atitudes de seu personagem. Por ter alguém (personagem) sob sua responsabilidade o aluno se preocupa em conduzi-lo da melhor forma e, por isso, muitas vezes o instiga a querer entender o que está acontecendo na estória, planejar suas ações e pensar nas conseqüências para somente depois executar as ações (OKLANDER, 1978). Sendo assim, o aluno aprende a fazer, pois ele não somente executa ações, mas entende e planeja antes de agir. Por intermédio do professor, o aluno pode ter algum feedback durante a estória informando se o que foi executado teve sucesso ou não, permitindo a ele refletir sobre o que o aconteceu e observar se é válido ou não repetir a ação.

Se durante a estória o aluno tiver vários caminhos disponíveis a serem percorridos, ele poderá explorá-los para saber qual é o melhor. $O$ aluno pode investigar as diversas situações para saber o que acontece, sendo assim, o aluno aprende a aprender, pois ele tem que investigar os caminhos possíveis, pesquisar sobre o que pode acontecer ao percorrer um determinado caminho.

Por ter a oportunidade de escolher o que deseja fazer durante a estória, o aluno aprende a fazer escolhas, expor sua opinião e a valorizar o que sabe e conhece, enfim valorizar sua cultura, seu conhecimento, pois com base nessas informações que ele conduz o jogo. Sendo assim, o aluno aprende a ser. Segundo Gadotti (1991) saber escolher é uma macrocompetência fundamental para uma pessoa. Pois ela já se experimenta como cidadão e como futuro profissional dentro da escola.

Por ter tais características surge a possibilidade de utilizar os jogos narrativos na sala de aula, como uma ferramenta para apoiar o professor em promover uma atividade que permita o aluno conviver com seus colegas e se expressar de uma forma espontânea e natural a ele. E através das estórias e da forma com que ele interage poderá aprender algumas habilidades que serão essenciais para sua vida pessoal, educacional e profissional.

Neste contexto, este trabalho relata a proposta de um jogo narrativo que possui características de RPG, Role-Playing Game. O RPG é um jogo narrativo de interpretação de personagens e tem como uma das características possibilitar a cooperação entre os jogadores, permitindo a socialização. Assim como o RPG o jogo apresentado tem como participantes o mestre ou narrador, que geralmente é o jogador mais experiente e tem a função de apresentar ao grupo uma estória, contendo personagens, suas 
características, cenários, enfim descrições necessárias para compor uma aventura contendo enigmas, situações e conflitos que exigirão escolhas por partes dos outros participantes, que são os jogadores.

Esses jogadores não são meros espectadores, são participantes que contribuem ativamente na estória, que através de personagens representam um papel e, escolhem caminhos e tomam decisões por sua própria conta, e muitas vezes não previstas pelo mestre, contribuindo para o desenvolvimento da estória de forma espontânea e inesperada (BRAGA, 2000). O mestre, durante o desenvolvimento da estória, pode interferir na narração, descrevendo os cenários, as características dos ambientes que aparecem na narração, os objetos e propondo situações para que os personagens possam interagir.

No contexto deste trabalho, o mestre é o professor que apresenta a estória e intervém na narração, de forma colaborativa com os jogadores, que são os alunos, co-autores da narrativa. O jogo está sendo desenvolvido para crianças entre 8 e 12 anos. Pois de acordo com Piaget (1998) nessa faixa etária a criança está no estágio Pensamento Operacional Concreto no qual possui grande interesse por jogos e descobre novos modos de jogar e trabalhar colaborativamente, características essas importantes para um jogo que tem como finalidade contar estórias colaborativamente.

Nesse estágio a criança desenvolve instrumentos acadêmicos vitais como a leitura, escrita e matemática básica, e torna-se capaz de focalizar sua atenção. Assim, a criança possui capacidade de ler a estória que está sendo contada a ela e de ajudar a escrevê-la, através da participação na construção da estória, bem como estar atenta em toda a estória (BEE, 1996).

No Pensamento Operacional Concreto também há o interesse da criança em ter amigos e querer participar e interagir com as brincadeiras de outras crianças, sendo assim, há grandes chances da criança se interessar em participar e interagir com a estória que está sendo contada de forma colaborativa envolvendo-a com outras crianças e o professor.

\subsection{Interface do Jogo Narrativo}

A Figura 1 mostra a interface disponível aos jogadores, no qual cada jogador visualiza sua carta (I); seu dado (II); a área de texto (III), que o permite ler todas as mensagens enviadas por ele e pelos outros jogadores e mestre durante a composição colaborativa da estória; no (IV), a carta em destaque, com outra cor e tamanho, representa o mestre do jogo e, a área (V) mostra as cartas dos demais jogadores.

Cada carta (I) permite ao jogador inserir uma imagem, tal característica possibilita ao aluno (jogador) se expressar não somente através da estória, mas também através da figura escolhida, pois o aluno pode escolher uma imagem que apresente o seu personagem 
triste, alegre, com raiva, entre outras. Essas emoções e suas expressões podem ser mais uma característica a ser considerada pelo professor (mestre) no processo de observação e condução do contar a estória, a fim de melhor conhecer seus alunos.

$O$ dado é a peça do RPG que informa ao mestre e ao jogador se uma determinada ação é possível ou não (SILVA et al., 2008). Por exemplo, para levantar algum objeto é necessário que o jogador tenha o valor do elemento força igual ou superior ao valor do peso do objeto, que é definido através do dado jogado pelo jogador. Assim, o jogador poderá levantar o objeto se o valor da sua Força for igual a $\mathrm{N}$ e o valor do dado for de 1 à $\mathrm{N}$, porém se o valor do dado for superior a $\mathrm{N}$ essa ação não será possível, pois o objeto pesa mais que a força que o jogador possui. Cada jogador, através da interface do jogo, visualiza todos os outros jogadores e o mestre, juntamente com os valores de seus elementos e suas respectivas imagens.

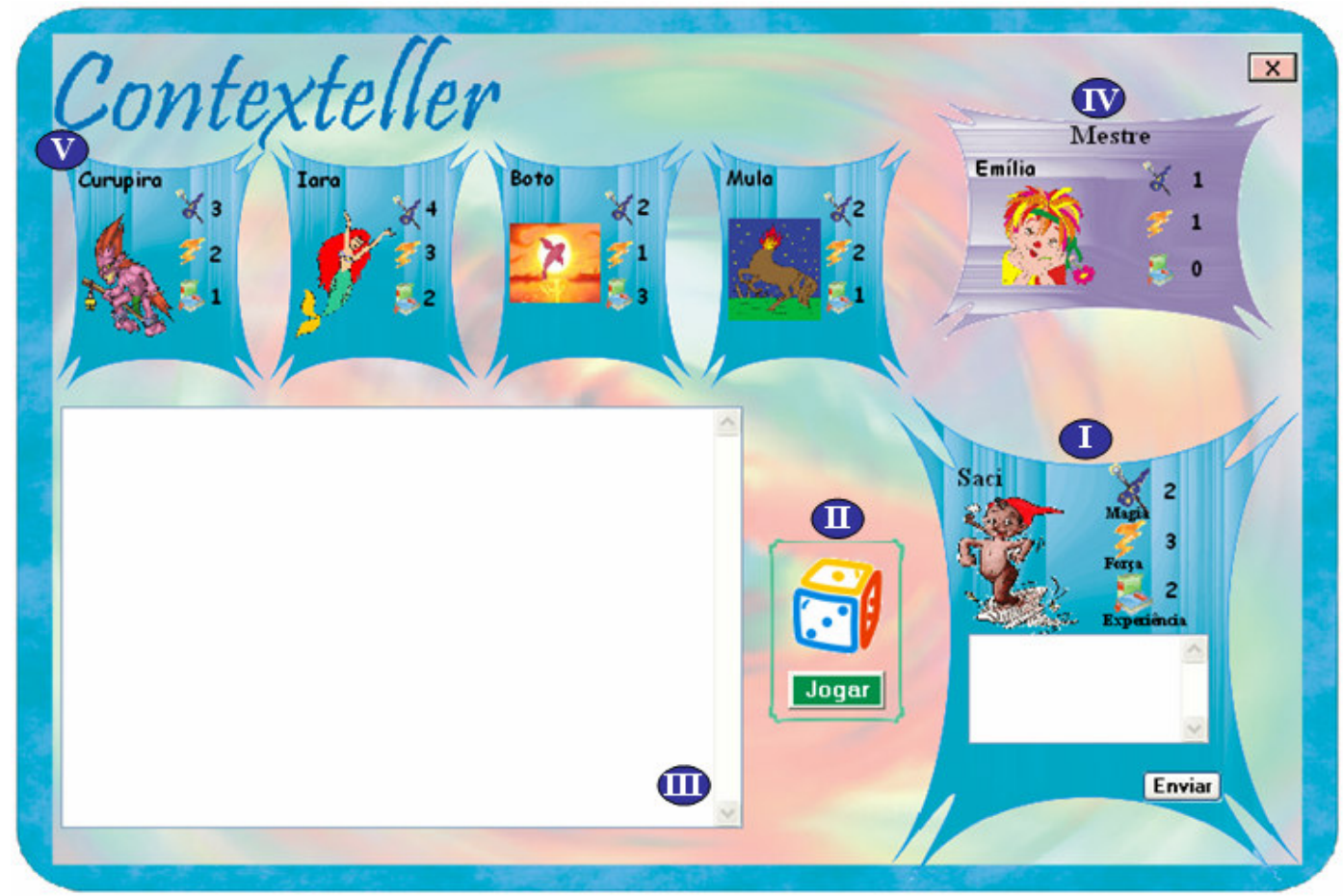

Figura 1. Interface

O jogo possui determinados elementos de RPG, que são: Magia, Força e Experiência. Nos dois primeiros elementos os valores são definidos pelos próprios jogadores, considerando um total de pontos previamente definido pelo mestre. Tais elementos são considerados como uma das regras existentes no RPG, pois evitam muitas discussões que porventura possam ocorrer durante a estória, como definir qual é o personagem mais forte, ou qual tem mais poder (SILVA et al., 2008). Pois, uma vez definido os valores, há um número a ser considerado em tais situações. Por exemplo, um personagem com "Força 5" possui maior probabilidade de sobreviver num embate do que um personagem com "Força 2". 
O valor da Experiência é atribuído também pelo mestre, quando o personagem consegue atingir uma determinada meta estipulada durante o desenvolvimento da estória, ou seja, dinamicamente. Esse ultimo elemento instiga o aluno a jogar com atenção e a querer enfrentar e vencer os desafios propostos. O mestre pode oferecer vantagens aos jogadores com maior experiência, como por exemplo, quando é necessário escolher entre caminhos a serem percorridos em uma determinada estória, o mestre pode permitir que o jogador com o maior valor de Experiência possa definir entre os caminhos; como também este valor pode acrescentar vantagens com relação aos outros elementos da carta do personagem. Portanto, estes elementos em conjunto com a narração do mestre proporcionam a competição no jogo, mesmo que indiretamente. Segundo Crawford (1982) uma importante propriedade do jogo é o conflito. Ele relata que não existe jogo sem este componente, mesmo quando não está ocorrendo uma competição entre os jogadores diretamente.

A interface do jogo possui 6 cartas, pois considerou-se a participação de até 5 jogadores e 1 mestre, que é o número utilizado normalmente em um jogo de RPG de cartas (FERNANDES, 2008). Com o máximo de 5 jogadores, visa-se também facilitar ao mestre (professor) acompanhar toda a estória que está sendo contada pelos jogadores (alunos), pois caso o número de jogadores fosse maior, o mestre poderia ter dificuldades em ler todas as mensagens enviadas, interagir adequadamente para a condução da narração, observar o desenvolvimento do enredo que cada personagem propõe e seu comportamento.

Uma vez que o jogo proposto tem como objetivo permitir ao professor conhecer seus alunos, possibilitar aos alunos se expressarem e trabalharem colaborativamente é necessário que o professor esteja atento a todas as mensagens, para também interagir e instigar os alunos a continuar a estória.

Para permitir aos jogadores maior identificação com a linguagem, personagens, cenários, enfim com a estória, permitindo à eles perceberem significado na semântica do que está sendo contado e, com isso ter maior interesse em participar da estória, este jogo considera à cultura, os valores, as crenças, enfim o senso comum dos jogadores, para a contextualização da estória.

Com o jogo, deseja-se dar apoio computacional ao mestre para conseguir ajuda, a partir de informações contextualizadas, na fase inicial, na composição do cenário, dos personagens a serem apresentados e; na fase de intervenção da narrativa, para roteirização e sequenciação da estória, pois o professor pode ter apoio para narrar à estória. Esse apoio é obtido através do conhecimento de senso comum que representa aspectos culturais da comunidade a qual os alunos pertencem.

\subsection{O uso do senso comum no apoio ao jogo narrativo}


O jogo aqui proposto faz uso do senso comum obtido através do Projeto Open Mind Common Sense no Brasil (OMCS-Br), desenvolvido pelo Laboratório de Interação Avançada (LIA), da UFSCar em colaboração com o Media Lab do Massachusetts Institute of Technology (MIT) (ANACLETO, 2008).

$\mathrm{O}$ site do Projeto OMCS-Br pode ser acessado por qualquer pessoa através do endereço http://www.sensocomum.ufscar.br. Ao entrar no site a pessoa pode se cadastrar e ter acesso a diversas atividades e temas disponíveis. Um dos temas disponível é sobre o Universo Infantil, que permite as pessoas falarem sobre situações, personagens existentes no Universo Infantil - Folclore, Contos de Fadas, entre outras. Este tema foi desenvolvido com objetivo de utilizar o conhecimento de senso comum, coletado das pessoas a respeito do Universo Infantil neste jogo narrativo, porém ressalta-se que este jogo faz uso de toda a base de conhecimento de senso comum, ou seja, utiliza todas as informações coletadas dos demais temas e atividades.

No jogo proposto, as informações de senso comum são obtidas através de cartas, com o formato semelhante às cartas dos personagens. As cartas de senso comum estão presentes nas interfaces do professor para apoiá-lo durante a elaboração e sequenciação da estória. Para iniciar o jogo o professor precisa executar 5 passos, definindo:

$1^{\circ}$ Passo: as informações de senso comum que deseja ter acesso. Este passo é necessário para o professor obter as informações de senso comum específicas de determinada região a qual pertencem às crianças que ele deseja contar uma estória. Para tanto, é necessário que ele defina dentre os estados do Brasil qual(ais) será(ão) considerado(s). A partir desta informação é realizado um filtro em toda a base de senso comum para separar o conhecimento de certa região, no qual o professor terá acesso. Assim, ele poderá criar sua estória considerando o contexto e a realidade cultural dos alunos.

$2^{\circ}$ Passo: quais serão os alunos que participarão do jogo. Esta informação se faz necessária para o professor ter acesso futuro a toda estória criada e aos alunos que participaram de sua construção. Algumas informações pertinentes são: nome, idade, sexo, escolaridade, país, entre outros.

$3^{\circ}$ Passo: o assunto da estória e o seu título. Neste passo o professor pode usar uma carta de senso comum. Ao digitar qualquer palavra na carta é feita uma busca na base e o professor obtêm informações relacionadas a esta palavra. Por exemplo, se o professor digita "floresta", ele pode obter do senso comum características, personagens, vegetação, animais e outras informações que aquela região, a qual pertence às crianças, acredita ter na floresta.

$4^{\circ}$ Passo: quais serão os personagens que irão fazer parte da estória, para tanto neste passo (Figura 2) o professor tem que definir a quantidade e quais serão os personagens. Sendo no máximo 6 personagens, ou seja, 6 cartas -5 representam os alunos (I) e 1 representa o professor (II). Para auxiliar o professor na definição dos nomes e características dos personagens estão disponíveis duas cartas de senso comum.

Na primeira (III), a partir de alguma característica inserida na carta é feita uma busca na base e são obtidos nomes de personagens que possuem essa característica, como exemplo, ao inserir alguma característica, dentre: fazer traquinagens, piadas, 


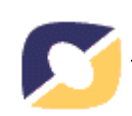

assustar crianças, o professor pode visualizar: Saci-Pererê, Iara, Curupira, Caipora (Folclore Brasileiro), Curinga (Filme do Batman), entre outros.

O professor também pode obter características de um personagem específico, sendo necessário apenas digitar o seu nome na segunda carta (IV). Por exemplo, ao digitar: Iara, o resultado pode ser: sereia, cabelos longos, bonita, cauda de peixe, metade mulher metade peixe, etc. O professor poder unir estas informações com a estória que ele deseja criar e assim definir os personagens, suas características e personalidades.

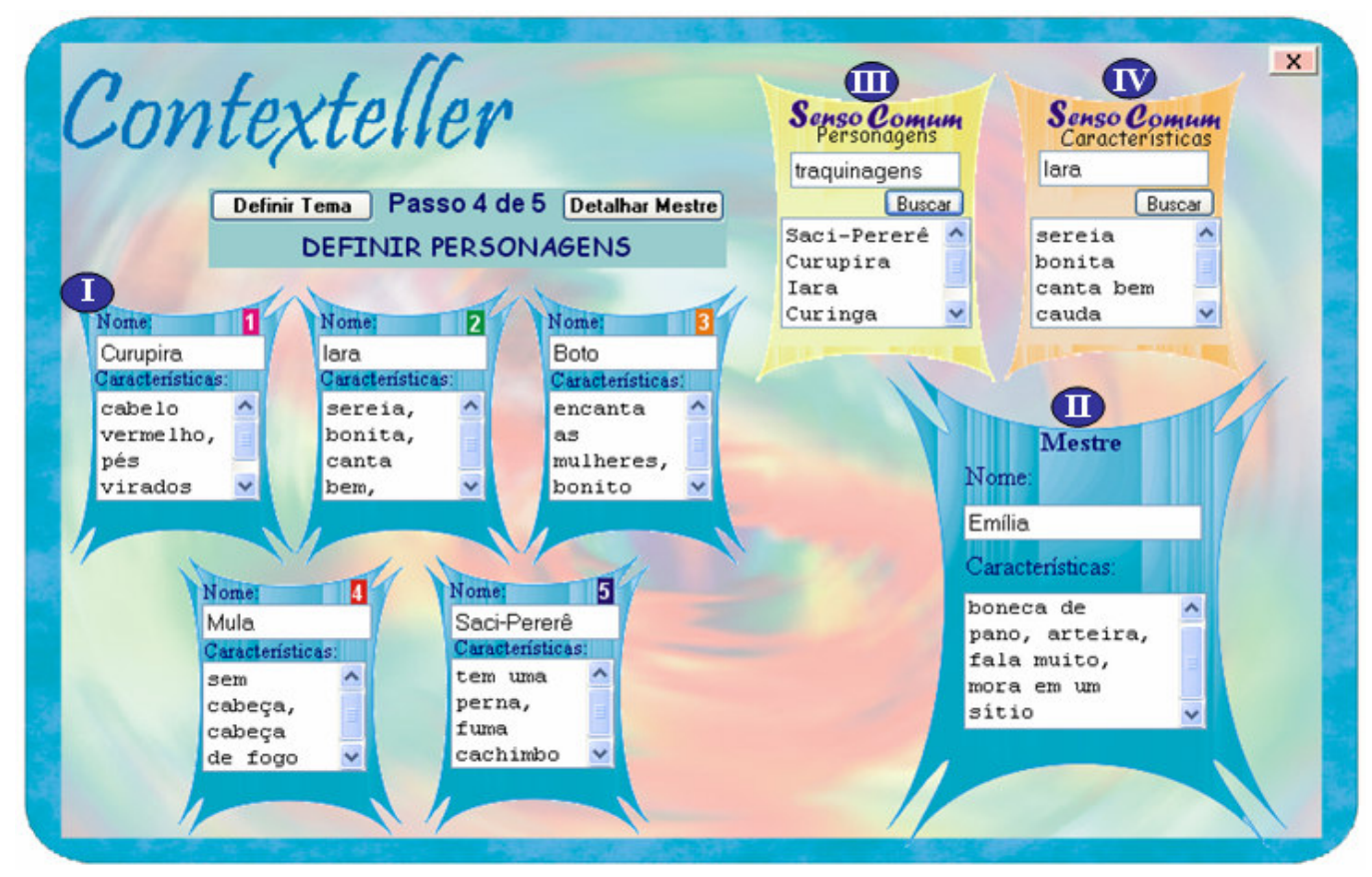

Figura 2. Interface do mestre para definir os

$5^{\circ}$ Passo: Após definir os personagens, o professor pode detalhar o seu personagem, escolhendo uma imagem para representá-lo, como também definir os valores dos elementos Magia e Força (Figura 3). Neste passo também se pode alterar alguma característica do seu personagem. 


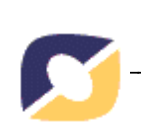

Após realizar estes 5 passos, o jogo está pronto para ser acessado pelo alunos. Para participarem da estória eles precisam escolher um personagem, em uma interface semelhante à Figura 2. Da mesma forma que acorre com o professor, o aluno ao escolher um personagem poderá detalhá-lo, escolhendo uma imagem e definindo os valores dos elementos Magia e Força (Figura 3). Essa imagem que pode aparentar estar

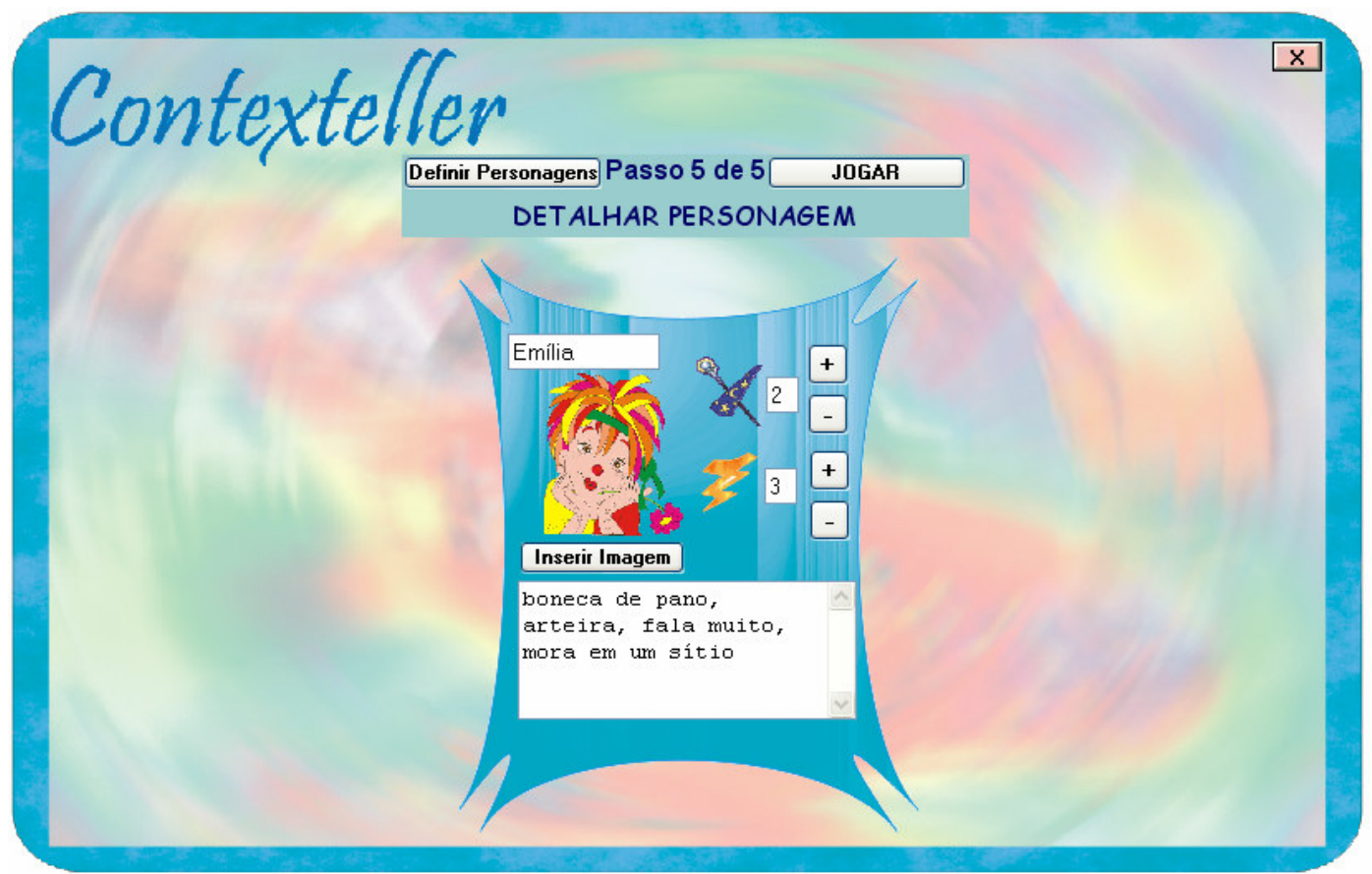

triste, alegre, nervoso, etc, pode ser uma característica a ser considerada pelo professor durante a estória.

O senso comum também poderá ser utilizado durante a estória, para sua sequenciação, apoiando o professor de modo que ele possa dar continuidade à estória, assim como nos passos anteriores. O senso comum será obtido através de uma carta, em uma interface do jogo específica para o professor, semelhante à Figura 1.

Para ilustrar uma situação, no decorrer da estória uma jogadora que escolheu ser a personagem Iara, diz: "Eu (como Iara) não quero sair agora, pois ainda tenho que pentear meus cabelos".

Todas as regiões do Brasil consideram que a Iara é uma sereia, porém em algumas regiões ela tem algumas características diferentes, tais como: cabelo curto ou longo, loira ou morena, baixa ou alta, etc. Se o professor conhecer o senso comum de uma determinada região, ele poderá contar a estória considerando sua realidade cultural. Por exemplo, "Iara não quer sair, pois ela tem que pentear seus lindos e longos cabelos loiros".

\section{Conclusões}

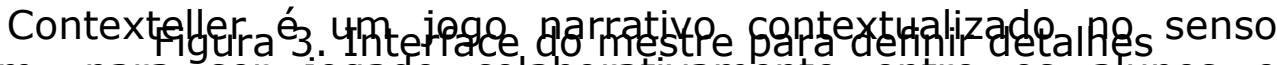
comum, para ser jogado colaborativamente entre os alunos e professor, considerando as questões culturais dos alunos para a 
contextualização da estória. O jogo narrativo sensível à cultura permite ao aluno se sentir próximo da estória, possibilitando se identificar, se expressar e trabalhar colaborativamente através do personagem em seu contexto cultural, conhecendo e identificando as características existentes na estória descritas pelo professor, a partir de sugestões vindas e adotadas do conhecimento de senso. O professor para incentivar a colaboração entre os alunos pode definir um objetivo em comum, por exemplo, algo que tem que ser encontrado no final da estória e, cada criança através de seu personagem precisa colaborar com os demais para atingir o objetivo.

Dependo da forma como a estória é conduzida o aluno pode experienciar a importância de ajudar e ser ajudado; valorizar sua cultura, sua estória e seu conhecimento para planejar e tomar as decisões necessárias durante a estória; saber unir as informações para definir suas metas e assim alcançar seu objetivo. O professor pode fazer uso das estórias contadas para gerar diversos materiais a ser apresentados e utilizados pelos alunos, como: imprimir a estória de modo que os alunos possam ter a estória em forma de livro, permitindo a eles levarem suas estórias para suas casas, como também mostrar aos seus colegas; permitir aos alunos desenharem nas folhas impressas para que possam desenhar a estória que eles mesmos criaram.

Ao ter a estória impressa para levar para a casa ou para desenhar, dá-se ao aluno a possibilidade de maior realização em ver o produto que ele ajudou a construir, motivando-o a participar de outras estórias, como também aumentar o interesse do aluno por aquilo que foi falado pelo professor e pelos seus colegas.

\section{Referências Bibliográficas}

ANACLETO, J. C.; FERREIRA, A. M.; PEREIRA, E. N.; SILVA, M. A. R.; FABRO, J. A. Ambiente para criação de jogos educacionais de adivinhação baseados em cartas contextualizadas. In: WIE Workshop sobre Informática na Escola, 2008

BEE, H. "A criança em Desenvolvimento". São Paulo: Harper \& Row do Brasil, 1996, 550p.

Disponível

BOTELHO, L. Jogos educativos aplicados ao e-Learning, 2003.

http://www.elearningbrasil.com.br/home/artigos/artigos.asp?id=1921,

Setembro 2007.

BRAGA, J. M. Aventurando pelos caminhos da leitura e escrita de jogadores de Role Playing Game (RPG). 2000. Dissertação de Mestrado, Programa de Pós-Graduação de Educação, UFJF, 2000, 92 p.

CASALI, A. Educação vital para a escola. Revista Educação, n. 2, Maio/Agosto 2005, pp. 297-315.

CASSELL, J.; RYOKAI, K. Making Space for Voice: Technologies to Support Children's Fantasy and Storytelling. In: Springer-Verlag, 2001. 22p.

FERNANDES, V. R. O que é RPG?. Revista RPG Dragão Brasil, n. 123.

FREIRE, P. R. N. Pedagogia da autonomia: saberes necessários

à prática educativa. 31 ed. Rio de Janeiro: Paz e Terra, 1996. 
GADOTTI, M. Perspectivas atuais da educação. São Paulo em Perspectiva, vol. 14 n. 2, Junho 2000.

GADOTTI, M. Significado e desafio da educação básica. In: International Workshop - World University Service (WUS), 1991. $189 p$.

MARCATTO, A. Saindo do Quadro. São Paulo: Alfeu Marcatto, 1996.

OAKLANDER, V. Descobrindo Crianças a abordagem gestáltica com crianças e adolescente. São Paulo: Summus Editorial, 1978, 364p.

PAPERT, S. Logo: computadores e educação. J A Valente (Trad.). SP: Brasiliense, 1985.

PIAGET, J. Psicologia e pedagogia. Rio de Janeiro: Forense, 1998. 184p.

SILVA, M. A. R.; ANACLETO, J. C. A Narrative Game Culturally Contextualized by Common Sense Modeled as a Semantic Network. In: WSWEd@SBIE - Workshop on Semantic Web and Education, 2008

TAROUCO, L. M. R; ROLAND, L. C. ; FABRE, M. J. M.; KONRATH, M. L. $P$. Jogos educacionais. In: CINTED - Centro Interdisciplinar de Novas Tecnologias na Educação, 2004.

VYGOTSKY, L. A formação social da mente. São Paulo: Martins Fontes, 1987. 